\title{
The journal of community genetics
}

\author{
Jörg Schmidtke • Leo P. ten Kate
}

Published online: 2 April 2010

(C) The Author(s) 2010. This article is published with open access at Springerlink.com

The new journal Journal of Community Genetics sets another landmark in the history of community genetics. In 1987, the term "community genetics services" was first used in a WHO document to describe clinical genetic activities offered directly to the population, and the need for research in this area of medical practice was soon realized (Modell et al. 1991; Modell 1992). In 1998, the journal Community Genetics was founded (Ten Kate 1998) and, for 11 years, served as a forum for all research activities in the field. The new Journal of Community Genetics follows this tradition as the only periodical publication worldwide devoted to this branch of medicine. It is an official journal of the International Society of Community Genetics and Genomics, founded in 2009, and fulfills the prophecy that a good concept may temporally be invisible but, as a submarine, will surface somewhere (Ten Kate 2008). Meanwhile, the international multidisciplinary community genetics e-mail network has more than 800 members at the time of writing and continues to grow.

We believe that community genetics and "public health genetics" are not the same, although they have much in common. The principal aim of public health genetics is to improve population health by reducing disease prevalence. The ultimate aim of community genetics is the well-being of the individual in that population. These different aims can be in conflict, particularly in the area of reproductive medicine. An informal group of 14 scientists from Europe,

J. Schmidtke $(\square)$

Institut fuer Humangenetik, Medizinische Hochschule Hannover,

Carl-Neuberg-Str. 1,

30625 Hanover, Germany

e-mail: schmidtke.joerg@mh-hannover.de

L. P. ten Kate

Department of Clinical Genetics, VU University Medical Center,

PO Box 7057, 1007 MB Amsterdam, The Netherlands
Africa, Asia, Australia, North America, and South America has recently reached the consensus definition:

Community Genetics is the art and science of the responsible and realistic application of health and disease-related genetics and genomics knowledge and technologies in human populations and communities to the benefit of individuals therein. Community Genetics is multi-, inter- and transdisciplinary and aims to maximize benefits while minimizing the risk of harm, respecting the autonomy of individuals and ensuring equity. (Ten Kate et al. 2010).

The main areas of research in community genetics were identified by these authors to include:

- Genetic screening

- Genetic literacy and education

- Access and quality of genetic services

- Genetics in primary care

- Genetics in middle-income and low-income countries

- Genetics in disadvantaged subpopulations

- Registries of congenital and genetic disorders

- Genetics in preconception care

- Public consultation on genetic issues

- Epidemiological issues

- Economic issues

- Psychosocial issues

- Ethical and legal issues

- Policy issues

The Journal of Community Genetics invites the scientific community to submit research on all these activities.

The journal will present original research papers, reviews, short communications, case and country reports, commentaries, news, and correspondence. The journal will serve as a forum for community genetics worldwide, with a focus on 
low-income and middle-income countries, many of which now experience the epidemiological transition from infectious disease to genetic disease as major constituents of population and individual disease load. This is reflected by the composition of the board of associate editors and by the members of the advisory board, rendering this Springer periodical a journal with an impressively broad geographic distribution of scientific support.

We would like to thank the publisher for their engagement in a field of research that is likely to impact, in the near future, on a dramatically increasing number of communities and individuals worldwide, yet remains heavily underdeveloped and underfunded even in the majority of developed countries. We hope that this journal will help to increase the visibility of community needs and demands for genetic services, and the necessity for research in this area.

Jörg Schmidtke and Leo P. ten Kate
Open Access This article is distributed under the terms of the Creative Commons Attribution Noncommercial License which permits any noncommercial use, distribution, and reproduction in any medium, provided the original author(s) and source are credited.

\section{References}

Modell B (1992) The need for a science of community genetics. Birth Defects Orig Artic Ser 28(3):131-141

Modell B, Kuliev AM, Wagner M (1991) Community genetics services in Europe: report on a survey. European Series, No. 38. WHO Regional Publications, Copenhagen

Ten Kate LP (1998) Editorial. Community Genet 1:1-2

Ten Kate LP (2008) Editorial: discharge and farewell. Community Genet 11:312

Ten Kate LP, Al-Gazali L, Anand S, Bittles A, Cassiman JJ, Christianson A, Cornel MC, Hamamy $\mathrm{H}$, Kääriäinen $\mathrm{H}$, Kristoffersson U, Marais D, Penchaszadeh VB, Rahaman P, Schmidtke J (2010) Community genetics: its definition, 2010. J Community Genet (this issue) 